\title{
Eating behavior and physical activity of senior citizens during the COVID-19 lockdown
}

\author{
Denson M. Liday, Mary Rose C. Liwag \\ College of Health Sciences, Quirino State University, Philippines
}

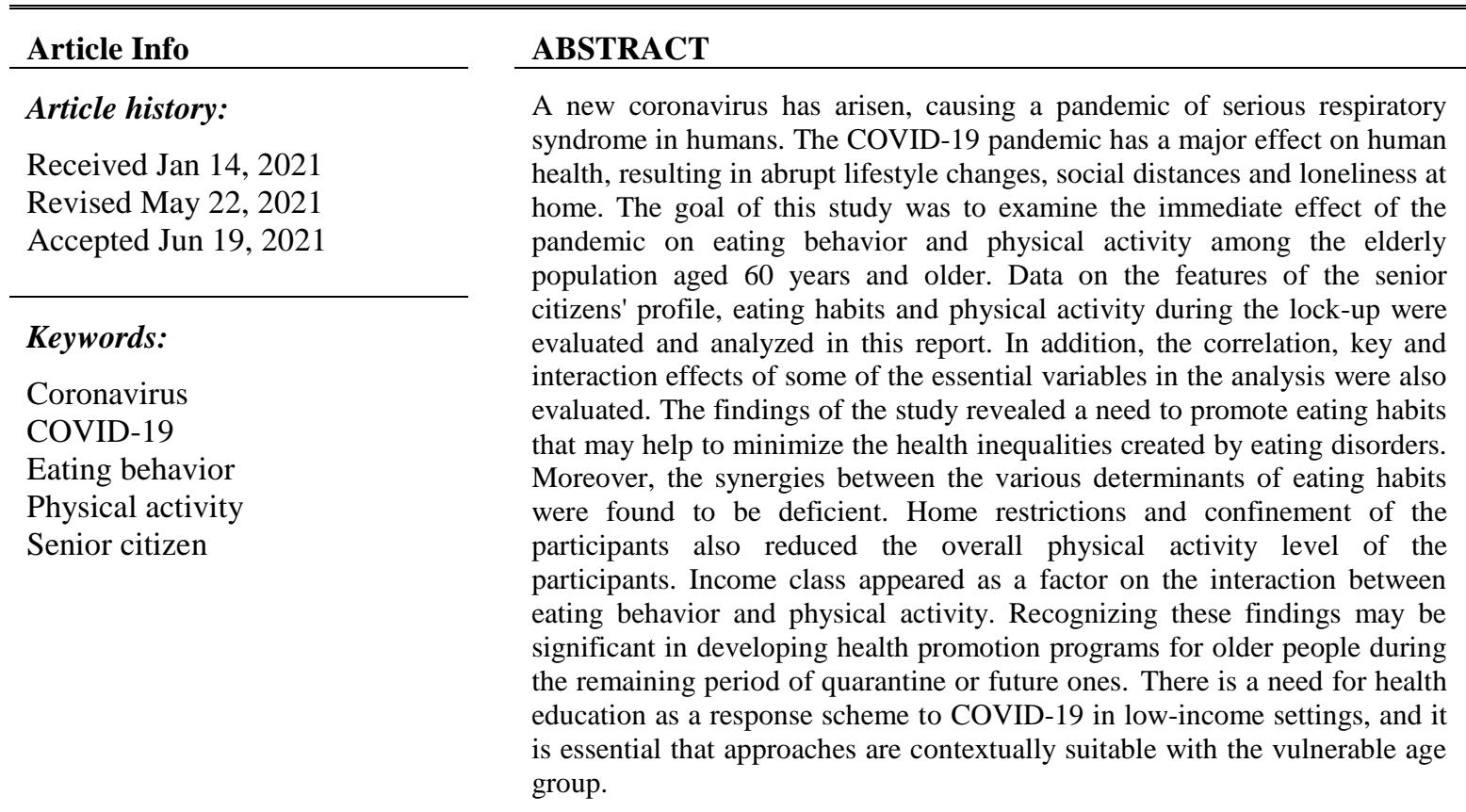

This is an open access article under the CC BY-SA license.

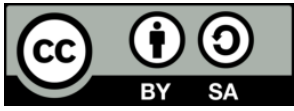

\section{Corresponding Author:}

Denson M. Liday

College of Health Sciences

Quirino State University

Diffun, Quirino, Philippines

Email: densonmarianoliday@gmail.com

\section{INTRODUCTION}

The novel coronavirus disease (COVID-19) is an infectious respiratory disease that first infected humans at the end of 2019 and was declared a global pandemic by the World Health Organization (WHO) on March 11, 2020 (World Health Organization, 2020). After the outbreak of the virus, countries all over the world have adopted various levels of protective measures and restrictions to delay or avoid its spread, including "social distances" or "physical distances," resulting in unparalleled impacts on social relations, jobs and the world economy [1]. In a struggle to control the spread of COVID-19 in the Philippines, On March 15, 2020, the government has implemented the general community quarantine (GHQ) [2]. Physical distance and self-isolation have had a strong effect on the lives of people, influencing, in particular, eating patterns and daily behavior [3].

In the Philippines, while the crisis of COVID-19 has impacted people of all walks of life, there is an unheard-of aspect to the insecure elderly, the elderly. The inter-agency task force (IATF) for the 
Management of Emerging Infectious Diseases established in its Guidelines that any person under the age of 21 years of age, those under the age of 60 years of age or older, those with co-morbidity, immunodeficiency or other health threats, and pregnant women, including any person residing with the said person, are required to remain in their residence. With these rules, the movement of senior citizens has been restricted and has been especially influenced by certain social attributes. Specifically, under the Strengthened Community Quarantine, all modes of local transport, including land, air and sea, have been suspended and residents have not been allowed to leave their homes except in the event of an emergency [4], [5].

Health awareness is one of the demands of COVID-19 [6]. Restricted exercise has influenced people's dietary and lifestyle habits as people appear to pursue immune-boosting herbs/nutrients and have replaced outdoor activities with sedentary indoor performances [7]. Moreover, household confinement was also linked with unhealthful dietary habits as people reported an increase in the frequency of consuming unhealthful food, eating out of control, snacking between meals, and an increase in the number of meals per day [8]. During a pandemic-associated national quarantine, a large percentage of people can experience variations in dietary behaviors, increased eating and snacking, and weight transformation [9].

This study discusses the condition of senior citizens in the Philippines during the COVID-19 lockdown in terms of their eating behavior and physical activity. Several enabling laws through the constitution, executive orders, and republic acts have been enacted to protect the welfare of senior citizens; however, the current crisis has revealed ageism issues such as inaccessibility to essential needs, inadequate physical space, and nutrition concerns to senior citizens. This paper recommends the need to translate the laws into effective programs, discuss related ageism concerns with sensitivity, and consider evidence of successful national and local efforts to further improve the condition of the senior citizens in the country. The Philippines is listed as one of the countries with an aging population, as the proportion of people aged 60 and over is $7.4 \%$ in 2015 and is expected to rise to $15.9 \%$ by 2045 , and senior citizens appear to have a higher prevalence of various medical conditions and comorbidities [10]. In the Philippines, communicable diseases are still prevalent and, considering the poor resistance of senior citizens, they have been more likely to suffer due to poverty and restricted access and insufficient health facilities, and Filipinos' senior citizens and their families are still unaware of the cognitive problems related to old age and family carer burnout, thus requiring comprehension [11].

With this considerable challenge and endeavor in our present system related to senior citizens, this study was conducted to add knowledge and fill in some of the gaps of health researches focused on providing essential information and facts on the issue of health practices involving senior citizens. This paper is an essential step in an attempt to evaluate if necessary health practices were being achieved by the participants based on assessments and hoped that it may likely influence and challenge the government and other related agencies in crafting programs as a way to help the said participants on this aspect of human life in the society. As many have pointed out, COVID-19 is much more than a health crisis. It has amplified the incapacity of most systems around the world to socially, economically, and medically protect the most susceptible in societies [12]. Furthermore, it is envisioned that the present study may offer an opportunity for senior citizens to express their views and experiences, in a non-threatening environment about the challenges they face in relation to their health practices. Generally, this study aimed to assess by determining the interplay between the eating behavior and physical activity among senior citizens in a municipality of the province of Quirine.

To explore the main purpose of the study, six specific problems guided the study, namely: (i) What are the profile characteristics of the respondents? (ii). What is the extent of eating behavior of the respondents? (iii). Are there eating behavior variables which are highly or least favored by the participants? (iv). What is the extent of physical activity of the participants? (v). Is there a significant main and interaction effect of the income class to the eating behavior and extent of physical activity of the participants? (vi). Is there a significant correlation between the variables, eating behavior, extent of physical activities and income class of the participants? This research was based on the social cognitive theory (SCT) in which this theory on SCT is a useful model to design and deliver an intervention that provides a complete approach to promote health [13]. Social Cognitive Theory also includes the human, social and environmental determinants of health, SCT-based interventions have resulted in enhanced diet and physical activity levels [14]. Figure 1 shows the conceptual framework of the study.

The study utilized the three-box framework in which the variables are to be tested. The profile of the participants, eating behavior and extent of physical activity will be compared and correlated. Descriptive and inferential analysis results will be highlighted to satisfy the third box in the framework as shown by the arrow. 


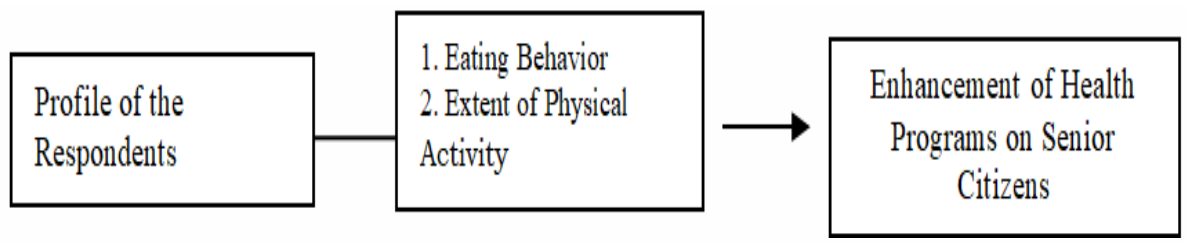

Figure 1. Conceptual framework of the study

\section{RESEARCH METHOD}

The cross-section survey was used as a research design in this report. In health, most studies are in the form of cross-sectional studies which are more beneficial than other designs in terms of health study [15], furthermore, cross-section design can be useful for planning, tracking and assessment of public health [16]. The study was conducted in the municipality of Diffun, Province of Quirino, Philippines. The target populations were the senior citizens with ages ranging from 60 years and older and had no communication impairments. The participants were selected through stratified random sampling based from the result of proportionate sampling conducted. The number of participants to represent the whole population was obtained using the software $G^{*}$ Power version 3.1.9. The instrument used an adapted survey questionnaire consisting of three sections. The first section determined the profile characteristics of the respondents. The second segment examined the magnitude of the respondents' eating activity in terms of food satisfaction, emotional overeating, food chaos, food responsiveness, sluggish eating, hunger, and satiety responsiveness. The adult eating behavior questionnaire (AEBQ) [17] has been modified to test the eating behavior of the respondents. The degree of eating activity per subclassification was calculated by the Likert 4-point scale. For the purpose of value reduction, a qualitative definition was designed to describe the mean score of each test. The third section evaluated the extent of physical activity of the participants using a dichotomous type of questions adapted from CHAMPS Physical Activity Questionnaire of Older Adults [18]. Responses were transposed into a percentage range of scores described with a verbal interpretation to determine its extent. For the reliability of the instrument, the study made used of Cronbach's Alpha coefficients to establish the internal consistency of each item in the instrument. In terms of its validity, credibility for its internal validity and authenticity, item level content validity index (I-CVI) using Kappa was utilized. The study utilized both descriptive and inferential statistics. Descriptive statistics like frequency and percent were utilized in describing the profile characteristics of the respondents. Mean and standard deviation were used to describe the extent of eating behavior, while frequency and percent were used to describe the extent of physical activity of the participants. Repeated measures by Pairwise comparisons were performed for other inquiries like determining the highly/least favored eating behavior. For the inferential statistics, Univariate statistics by Factorial Analysis was used if significant main and interaction effect is achieved when grouped by the selected profile variables. Spearman-rho correlation was used to determine the significant correlation between and among the selected profile variables, extent of eating behavior and physical activity of the participant.

\section{RESULTS AND DISCUSSION}

Significant findings of the study are presented in the tables that follow. A discussion of the implications of each finding is also included. The tables were arranged based on the order of research problems presented earlier.

\subsection{Profile of respondents}

Table 1 shows the profile of the participants. There were more female $(61 \%)$ than male participants, $(14.6 \%)$. In terms of income classification, majority of the participants belong to low income but not poor $(64.2 \%)$, more than one-fourth were poor $(27.6 \%)$, few belong to lower middle income $(7.3 \%)$ and middle class $(0.8 \%)$. This means that the majority of the participants claimed that they belong to Low income classification. Data from the Philippine Institute for Development Studies (PIDS) showed that $40 \%$ of the country's population belongs to the middle-income class, while the rest or $58 \%$ belong to the lower-income class [19]. The two causes of infection associated with COVID-19 include virus-related infections, and the other is the economic downturn that triggered it. Emerging evidence indicates that countries with adequate and more comprehensive health and social security programs do not need to resort to stringent crisis contagion steps, that strong investment is required to create greater inclusiveness and coverage of the country's health care system, and that this can rapidly re-align and increase absorption ability during a crisis if needed [20]. Since the majority of the participants belong to poor and low income, it means that they are vulnerable to the economic related contagion of this pandemic. 
Table 1. Profile characteristics of the participants

\begin{tabular}{lcc}
\hline \multicolumn{1}{c}{ Profile } & $\mathrm{f}$ & $\%$ \\
\hline Gender & & \\
Male & 48 & 39 \\
Female & 75 & 61 \\
Income class & & \\
$\quad$ Poor & 34 & 27.6 \\
Low Income but not poor & 79 & 64.2 \\
Lower Middle Income & 9 & 7.3 \\
Middle Class & 1 & .8 \\
$\quad$ Total & 123 & $100 \%$ \\
\hline
\end{tabular}

\subsection{Eating behavior}

Table 2 shows the extent of eating behavior traits of the participants. Generally, the participants exhibited a high level of eating behavior, high level of appetitive traits and food avoidance traits. Looking closely at the table however revealed disparities in their responses which may impact on the overall picture of the participants' eating behavior, and is important to point out. For example, among the eight traits, there were two variables that exhibited a low level of extent, both hunger and emotional overeating. A follow up check if there is a favored trait/s based on the mean scores was conducted. Pairwise comparison showed that enjoyment of food, food fussiness, and emotional undereating rank the highest and is significantly higher than the other items $[\mu 1(2.96)=\mu 4(2.93)=\mu 3(2.88)>\mu 5(2.71)>\mu 8(2.57)=\mu 7(2.51)=\mu 6(2.48)>\mu 2(1.92)$. Food fussiness, often referred to as "picky eating" or "selective/neophobic eating,". While emotional overeating ranks the lowest and is significantly lower than the other groups. Hunger and slowness in eating rank as second and third least favored. The eight traits assessed by the AEBQ include four food-approach traits (food-responsiveness, hunger, emotional overeating and food-avoidance traits) and four food-avoidance traits (Food Fussiness, Emotional Undereating, Satiety Responsiveness, and Slowness in Eating). The high degree of food turmoil and food responsiveness of the participants must be highlighted as a point of change. Some appetizing traits tend to be risk factors for eating disorders, including binge eating (food responsiveness, low levels of satiety responsiveness, emotional overeating, and preventative eating disorder (food irritability, satiety responsiveness, and low levels of eating pleasure) [21]. No risk factors for eating disorders on traits, appetite, slow eating, emotional eating, emotional eating, satiety responsiveness, and enjoyment of food for participants.

Table 2. Extent of eating behavior of the participants

\begin{tabular}{lccc}
\hline \multicolumn{1}{c}{ Eating behavior traits } & Mean & Std. beviation & Verbal interpretation \\
\hline 1. Enjoyment of Food & 2.9654 & .32850 & High level \\
2. Emotional Overeating & 1.9248 & .46709 & Low level \\
3. Emotional Under Eating & 2.8846 & .64223 & High level \\
4. Food Fussiness & 2.9329 & .30881 & High level \\
5. Food Responsiveness & 2.7100 & .40423 & High level \\
6. Hunger & 2.4824 & .40759 & Low level \\
7. Slowness in Eating & 2.5068 & .37777 & High level \\
8. Satiety Responsiveness & 2.5711 & .42407 & High level \\
Overall mean & 2.6223 & .15065 & High level \\
Appetitive Traits & 2.5207 & .20974 & High level \\
Food Avoidance Traits & 2.7238 & .22256 & High level \\
\hline
\end{tabular}

\subsection{Extent of physical activity}

Table 3 indicates the magnitude of the participants' physical activity. Generally speaking, the magnitude of the physical activity of the participants is at a low level as expressed in the overall percentage of 44.43. Similar findings have been obtained from some research on the decline in the physical activity of the participants caused by the COVID-19 pandemic. Home limitations and containment lowered the overall level of physical activity, as people were unable to adjust to training at home and the potential reasons may be deficiency of equipment and inadequate space [ 22 This is interesting because older adults' involvement in leisure and transport-related physical activities is generally regarded as the main means of increasing overall physical activity levels of older adults. [23]. Prolonged home stay led to increased sedentary behaviors due to a reduction on the amount of daily physical activity [24]. Health benefits of Physical Activity are well established, with higher levels and a higher frequency of physical activity associated with reduced risk and better health in a variety of main areas [25]. It is also well known that physical inactivity causes more than five million deaths worldwide and is undermining the economy of public health systems, which are also 
commonly represented as helping to minimize inflammation and inflammation in the sense of viral infections in order to encourage physical activity for health promotion and disease prevention [26]. As a result, future research should focus on how to solve low-level physical activity problems by providing information and understanding of the benefits and barriers of this problem. To this end, we agree that it is possible to intensify the degree of home-based training during quarantine. In order to maintain the normal level of physical activity among the participants in this research, we suggest following the scientific recommendations and asking the experts in sports sciences. We are concerned about the physical activity of the participants after the end of the quarantine if there is no appropriate campaign to encourage physical activity among them at home.

Table 3. Extent of physical activity of the participants

\begin{tabular}{lccc}
\hline \multicolumn{1}{c}{ Indicators } & $\mathrm{f}$ & $\%$ & Verbal interpretation \\
\hline Do you usually stay at home? & 93 & 75.6 & Very high \\
Do play cards, bingo, or board games with other people? & 4 & 3.3 & Very low \\
Do you go to a senior center? & 81 & 65.9 & High level \\
Do you attend church or take part in church activities? & 96 & 78 & Very high level \\
Do you visit with friends or family (other than those you live with)? & 68 & 55.3 & High level \\
Do you walk leisurely for exercise or pleasure? & 62 & 50.4 & Low level \\
Do you attend other club or group meetings? & 56 & 45.5 & Low level \\
Do you do volunteer work? & 49 & 39.8 & Low level \\
Do you walk to errands (such as to/ from a store or to take children to school)? & 56 & 45.5 & Low level \\
Do you do light work around house (such as sweeping or vacuuming) & 99 & 80.5 & Very high level \\
Do you do light gardening (such as watering plants)? & 111 & 90.2 & Very high level \\
Do you ride a bicycle? & 20 & 16.3 & Very low level \\
Do you do stretching or flexibility exercise? & 24 & 19.5 & Very low level \\
Do you jog or run? & 21 & 17.1 & Very low level \\
Do you go to the farm? & 46 & 37.4 & Low level \\
Do you do heavy work around the house (such as cleaning the house)? & 30 & 24.4 & Very low level \\
Do you do heavy gardening (such as spading, raking)? & 23 & 18.7 & Very low level \\
Do you do aerobic or aerobic dance? & 3 & 2.4 & Very low level \\
Do you walk uphill or hike uphill? & 28 & 22.8 & Very low level \\
Do you do other types of physical activity not previously mentioned? & 123 & 100 & Very high level \\
Extent of Physical Activity & & Low level
\end{tabular}

\subsection{Interaction effect}

Table 4 shows the main and interaction effect of the variables eating behavior and extent of physical activity with the income class of the participants. This test was conducted to test if the relationship between two variables depends on the level of the third variable. Looking closely at the table reveals that a significant main effect is exhibited between income class and eating behavior $(\mathrm{p}=0.000)$, and extent of physical activity and income class $(\mathrm{p}=0.000)$. Furthermore, there is a significant interaction effect of the two variables eating behavior and extent of physical activity to the income class of the participants $(p=0.000)$. This means that the relationship between physical activity and eating behavior depends on the level of income class of the participants. The income class also significantly affects the Eating Behavior and the Physical Activity of the participants as what was reflected by the result of main effect statistics. Lesser food spending is likely to be a significant contributor to less healthy food choices among inferior socio-economic groups [28]. This finding established a need to promote eating habits that can help to minimize health inequality among senior citizens. Income level should be included in the preparation of health promotion and improvement programs. Targeted health education is essential as a response to COVID-19 in low-income settings, and it is significant that interventions are contextually relevant.

Table 4. Main and interaction effect of income class to the extent of physical activity and eating behavior of the participants (dependent variable: income class)

\begin{tabular}{lccccc}
\hline$\quad$ Source & df & Mean square & F & Sig. & Decision \\
Eating behavior & 58 & .508 & 20.016 & .000 & With significant main effect \\
Extent of physical activity & 10 & .249 & 9.813 & .000 & With significant main effect \\
Eating behavior * Extent of physical activity & 3 & .466 & 18.375 & .000 & With significant main effect \\
\hline
\end{tabular}

\subsection{Correlation among selected variables}

Table 5 reveals the correlation between the variables, income class, eating behavior and extent of physical activity of the participants. The table reveals that there is no significant correlation between and 
among the three variables. This means that no significant relationship exists among the variables. Containment to one's home has a direct effect on people's lifestyle, together with eating habits and patterns of physical activity [29]. Notice that while all groups are affected by the COVID-19 disease, the elderly are at the highest risk [30]. As a time of social confinement is vital to the protection of community health, it is necessary to consider people's lifestyle patterns, such as physical activity, eating behavior and the economic wellbeing of this affected age group in our society.

\begin{tabular}{|c|c|c|c|c|}
\hline \multicolumn{2}{|c|}{ Spearman's rho } & \multirow{2}{*}{$\begin{array}{c}\text { Income class } \\
1.000\end{array}$} & \multirow[t]{2}{*}{ Eating behavior } & \multirow[t]{2}{*}{ Physical activity } \\
\hline Income class & $\begin{array}{l}\text { Correlation coefficient } \\
\text { Sig. (2-tailed) }\end{array}$ & & & \\
\hline Eating behavior & $\begin{array}{l}\text { Correlation Coefficient } \\
\text { Sig. (2-tailed) }\end{array}$ & $\begin{array}{l}.043 \\
.639\end{array}$ & $\begin{array}{c}1.000 \\
.\end{array}$ & \\
\hline Physical activity & $\begin{array}{l}\text { Correlation coefficient } \\
\text { Sig. (2-tailed) }\end{array}$ & $\begin{array}{l}.015 \\
.872 \\
\end{array}$ & $\begin{array}{l}.041 \\
.652 \\
\end{array}$ & 1.000 \\
\hline
\end{tabular}

\section{CONCLUSION}

Active life expectancy is rising all over the world. A Filipino male and female 60 years of age and older can expect many more years of safe life expectancy. However, we should prevent early disability, beyond individual lifestyle decisions; we must strive to achieve longevity in society. This is best done by a well-funded and well-planned health care system. We recognized a need to promote eating habits that can help to minimize health inequalities. Income class should be considered for health promotion and enhancement of physical activity preparation initiatives. Moreover, the synergies between the various determinants of eating habits should be considered when planning nutrition interventions. This study was a beginning step and may served as an additional body of knowledge in describing the Filipino senior citizens' perceptions of healthy eating behaviors and physical activity during lockdown and other forms of quarantine.

It is hoped in this study that future research and endeavors should focus on developing meaningful interventions for low levels of physical activity and eating disorders among older people. Education and information of the importance and benefits of physical activity should be given to both elderly and carers. An activity schedule indicating the execution and management of individual and structured activities should be prepared. Finally, our quest for prolonged existence and vitality needs to be tempered by a conviction that life is priceless, especially in those who are frail and aged. Recognizing these findings may be significant in developing health promotion programs for senior citizen during the remaining period of quarantine or future ones.

\section{REFERENCES}

[1] Phillipou A et al., "Eating and exercise behaviors in eating disorders and the general population during the COVID19 pandemic in Australia: Initial results from the COLLATE project," International Journal of Eating Disorders, vol. 53, no. 7, pp. 1158-1165.

[2] Dizon RL, "The heterogeneous age-mixing model of estimating the covid cases of different local government units in the National Capital Region, Philippines," Clinical Epidemiology and Global Health, vol. 9, pp 12-16, 2021, doi.org/10.1016/j.cegh.2020.06.003.

[3] Di Renzo L et al., "Eating habits and lifestyle changes during COVID-19 lockdown: an Italian survey," Journal Of Translational Medicine, vol. 8, no. 229, pp. 1-15, 2020, doi: 10.1186/s12967-020-02399-5.

[4] GOVPH, "COVID-19 Inter-Agency Task Force for the Management of Emerging Infectious Diseases Resolutions: Department of Health website," 2020. [Online]. Available from: https://www.doh.gov.ph/COVID-19/IATFResolutions

[5] Prasetyo YT, Castillo AM, Salonga LJ, Sia JA, and Seneta JA, "Factors affecting perceived effectiveness of COVID-19 prevention measures among Filipinos during Enhanced Community Quarantine in Luzon, Philippines: Integrating Protection Motivation Theory and extended Theory of Planned Behavior," International Journal of Infectious Diseases, vol. 99, pp. 312-323, 2020, doi: https://doi.org/10.1016/j.ijid.2020.07.074

[6] Hidayah N et al., "Winning the Needs of the Gen Z: Gamified Health Awareness Campaign in Defeating COVID19 Pandemic", Procedia Computer Science, vol. 179, pp. 974-981, 2021, doi: 10.1016/j.procs.2021.01.087.

[7] Mayasari NR et al., "Impacts of the COVID-19 Pandemic on Food Security and Diet-Related Lifestyle Behaviors: An Analytical Study of Google Trends-Based Query Volumes," Nutrients, vol. 12, no. 10, pp. 1-8, 2020, doi: 10.3390/nu12103103.

[8] Ammar A et al., "Effects of COVID-19 Home Confinement on Eating Behaviour and Physical Activity: Results of the ECLB-COVID19 International Online Survey," Nutrients, vol. 12, no. 6, pp. 1-13, 2020, doi: https://doi.org/10.3390/nu12061583.

[9] Sidor A and Rzymski P, "Dietary Choices and Habits during COVID-19 Lockdown: Experience from Poland," 
Nutrients, vol. 12, no. 6, 1-13, 2020, doi: 10.3390/nu12061657.

[10] Reyes CM, Arboneda AA, and Asis RD, "Silver Linings for the Elderly in the Philippines: Policies and Programs for Senior Citizens [Internet]. Think Asia. Philippine Institute for Development Studies; 2019 [cited 2020Oct9]. Available from: https://think-asia.org/handle/11540/11190.

[11] Arboneda, Arkin A.; Asis, Ronina D, "Silver liningsfor the elderly in the Philippines: Policies and programs for senior citizens, PIDS DiscussionPaper Series, No. 2019-09,” Philippine Institute for Development Studies (PIDS), Quezon City, 2019. [Online]. Available: http://hdl.handle.net/10419/211083.

[12] UNESCO, "Call for participation: Rethinking Social transformations: Inequalities in the Arab region in light of COVID-19," [Online]. Available from: https://en.unesco.org/news/call-participation-rethinking-socialtransformations-inequalities-arab-region-light-COVID-19

[13] Zacarías G, Levy T.S., Puente E.E., Garbus P., and García O.P., "Development of an intervention program to prevent childhood obesity targeted to Mexican mothers of school-aged children using intervention mapping and social cognitive theory," Evaluation and Program Planning, vol. 74, pp. 27-37, 2019, doi: 10.1016/j.evalprogplan.2019.02.008.

[14] Helena B, Maria Hagstromer, Jan H., and Liselotte S. E., "A multi-component universal intervention to improve diet and physical activity among adults with intellectual disabilities in community residences: a cluster randomised controlled trial," vol. 34, no. 11, pp. 3847-3857, 2013, doi: 10.1016/j.ridd.2013.07.019.

[15] Mendoza O., "Training module in Basic Research Methods (BRM)," Philippine National Health Research System, 2018

[16] Maninder S. S., "Methodology Series Module 3: Cross-sectional Studies," Indian Journal of Dermatology, vol. 61, no. 3, pp. 261-4, 2016, doi: 10.4103/0019-5154.182410.

[17] Hunot C, Fildes A, Croker H, Llewellyn CH, Wardle J, and Beeken RJ, "Appetitive traits and relationships with BMI in adults: Development of the Adult Eating Behaviour Questionnaire,” Appetite., vol. 105, pp. 356-63, 2016, doi: 10.1016/j.appet.2016.05.024.

[18] CADC, "CHAMPS Physical Activity Questionnaire for Older Adults," Center for Aging in Diverse Communities, 2020, [Online]. Available: https://cadc.ucsf.edu/champs

[19] Albert JRG, Santos AGF, and Vizmanos JFV, "Profile and determinants of the middle-income class in the Phiulippines," Research Information Department, Philippines Institute for Development Studies, Discussion paper series no. 2018-20. Available: https://pidswebs.pids.gov.ph/CDN/PUBLICATIONS/pidsdps1820.pdf

[20] Mendoza RU, “COVID-19: Navigating Inclusive Recovery towards the New Normal,” SSRN, pp. 1-35, 2020 [Online]. Available https://papers.ssrn.com/sol3/papers.cfm?abstract_id=3598116

[21] H. F. Zickgraf, E. Richard, N. L. Zucker, and G. L. Wallace, "Rigidity and Sensory Sensitivity: Independent Contributions to Selective Eating in Children, Adolescents, and Young Adults," Journal of Clinical Child and Adolescent Psycology, pp. 1-13. 2020, doi: 10.1080/15374416.2020.1738236.

[22] Neto Lde O, Elsangedy HM, Tavares VDde O, Teixeira CVLS, Behm DG, and Silva-Grigoletto MED, "\#TrainingInHome - Home-based training during COVID-19 (SARS-COV2) pandemic: physical exercise and behavior-based approach," Brazilian Journal of Exercise Physcology, vol. 19, no. 2, pp. 1-11, 2020, doi: 10.33233/rbfe.v19i2.4006.

[23] Liu Z., Kemperman A., Timmermans H., and Yang D., "Heterogeneity in physical activity participation of older adults: A latent class analysis," Journal of Transport Geography, vol. 92, 2021, doi: 10.1016/j.jtrangeo.2021.102999.

[24] Chen P., Mao L., Nassis G.P., Harmer P., Ainsworth B.E., and Li F., “ Coronavirus disease (COVID-19): The need to maintain regular physical activity while taking precautions," Journal of Sport and Health Science, vol. 9, no. 2, pp. 103-104, 2020, doi: 10.1016/j.jshs.2020.02.001.

[25] Langhammer B, Bergland A, Rydwik E, "The Importance of Physical Activity Exercise among Older People," Biomed Research International, vol. 2018, pp. 1-3, 2018, doi: https://doi.org/10.1155/2018/7856823.

[26] Pechey R, and Monsivais P, "Socioeconomic inequalities in the healthiness of food choices: Exploring the contributions of food expenditures," Preventive Medicine, vol. 88, pp. 203-9, 2016, doi: 10.1016/j.ypmed.2016.04.012.

[27] Lau LL et al., "Knowledge, attitudes and practices of COVID-19 among income-poor households in the Philippines: A cross-sectional study," Journal of Global Health, vol. 10, no. 1, pp. 1-11, 2020, doi: 10.7189/jogh.10.011007.

[28] Campbell JP and Turner JE, "Debunking the myth of exercise-induced immune suppression: redefining the impact of exercise on immunological health across the lifespan," Frontiers in Immunology, vol. 9, pp. 1-21, 2018, doi: 10.3389/fimmu.2018.00648.

[29] Naja F and Hamadeh R, "Nutrition amid the COVID-19 pandemic: a multi-level framework for action," Eur. J Clin. Nutr., vol. 74, no. 8, pp. 1117-1121, 2020, doi: 10.1038/s41430-020-0634-3.

[30] Butler MJ and Barrientos RM, "The impact of nutrition on COVID-19 susceptibility and long-term consequences," Brain, Behavior, and Immunity, vol. 87, pp. 53-54, 2020, doi: 10.1016/j.bbi.2020.04.040. 